\title{
Effects of handling and short-term captivity: a multi- behaviour approach using red sea urchins, Mesocentrotus franciscanus
}

Aneesh P.H. Bose ${ }^{1}$, Daniel Zayonc ${ }^{2}$ Nikolaos Avrantinis ${ }^{2}$ Natasha Ficzycz ${ }^{2}$, Jonathan Fischer-Rush ${ }^{2}$ Fiona T. Francis ${ }^{3}$, Siobhan Gray ${ }^{2}$, Faye Manning ${ }^{2}$, Haley Robb ${ }^{2}$, Coralee Schmidt ${ }^{2}$, Christine Spice $^{2}$, Aari Umedaly $^{2}$, Jeff Warden ${ }^{2}$, Isabelle M. Côté Corresp. ${ }^{3}$

${ }^{1}$ Department of Collective Behaviour, Max Planck Institute for Ornithology, Konstanz, Germany

2 Bamfield Marine Sciences Centre, Bamfield, Canada

3 Department of Biological Sciences, Simon Fraser University, Burnaby, Canada

Corresponding Author: Isabelle M. Côté

Email address: imcote@sfu.ca

Understanding the effects of captivity-induced stress on wild-caught animals after their release back into the wild is critical for the long-term success of relocation and reintroduction programs. To date, most of the research on captivity stress has focused on vertebrates, with far less attention paid to invertebrates. Here, we examine the effect of short-term captivity (i.e., up to four days) on self-righting, aggregation, and predatorescape behaviours in wild-caught red sea urchins, Mesocentrotus franciscanus, after their release back into the wild. Aggregation behaviour, which has been linked to feeding in sea urchins, was not affected by handling or captivity. In contrast, the sea urchins that had been handled and released immediately as well as those that were handled and held captive, took longer to right themselves and were poorer at fleeing from predators than wild, unhandled sea urchins. These results indicate that handling rather than captivity impaired these behaviours in the short term. The duration of captivity did not influence the sea urchin behaviours examined. Longer-term monitoring is needed to establish what the fitness consequences of these short-term behavioural changes might be. Our study nevertheless highlights the importance of considering a suite of responses when examining the effects of capture and captivity. Our findings, which are based on a locally abundant species, can inform translocation efforts aimed at bolstering populations of ecologically similar but depleted invertebrate species to retain or restore important ecosystem functions. 
2 Effects of handling and short-term captivity: a multi3 behaviour approach using red sea urchins,

4 Mesocentrotus franciscanus

5

6 Aneesh P.H. Bose ${ }^{1,2}$, Daniel Zayonc ${ }^{1}$, Nikolaos Avrantinis ${ }^{1}$, Natasha Ficzycz ${ }^{1}$, Jonathan

7 Fischer-Rush ${ }^{1}$, Fiona T. Francis ${ }^{1,3}$, Siobhan Gray ${ }^{1}$, Faye Manning ${ }^{1}$, Haley Robb ${ }^{1}$, Coralee

8 Schmidt $^{1}$, Christine Spice ${ }^{1}$, Aari Umedaly ${ }^{1}$, Jeff Warden ${ }^{1}$ and Isabelle M. Côté ${ }^{1,3}$

${ }^{1}$ Bamfield Marine Sciences Centre, Bamfield, British Columbia, Canada

$11{ }^{2}$ Department of Collective Behaviour, Max Planck Institute for Ornithology, Konstanz, Germany

$12{ }^{3}$ Department of Biological Sciences, Simon Fraser University, Burnaby, British Columbia, 13 Canada

Corresponding Author:

16 Isabelle M. Côté

17 Email address: imcote@sfu.ca 


\section{ABSTRACT}

20 Understanding the effects of captivity-induced stress on wild-caught animals after their release

21 back into the wild is critical for the long-term success of relocation and reintroduction programs.

22 To date, most of the research on captivity stress has focused on vertebrates, with far less

23 attention paid to invertebrates. Here, we examine the effect of short-term captivity (i.e., up to

24 four days) on self-righting, aggregation, and predator-escape behaviours in wild-caught red sea

25 urchins, Mesocentrotus franciscanus, after their release back into the wild. Aggregation

26 behaviour, which has been linked to feeding in sea urchins, was not affected by handling or

27 captivity. In contrast, the sea urchins that had been handled and released immediately as well as

28 those that were handled and held captive, took longer to right themselves and were poorer at

29 fleeing from predators than wild, unhandled sea urchins. These results indicate that handling

30 rather than captivity impaired these behaviours in the short term. The duration of captivity did

31 not influence the sea urchin behaviours examined. Longer-term monitoring is needed to establish

32 what the fitness consequences of these short-term behavioural changes might be. Our study

33 nevertheless highlights the importance of considering a suite of responses when examining the

34 effects of capture and captivity. Our findings, which are based on a locally abundant species, can

35 inform translocation efforts aimed at bolstering populations of ecologically similar but depleted

36 invertebrate species to retain or restore important ecosystem functions. 


\section{Introduction}

38

39

40

41

42

43

44

45

46

47

48

49

50

51

52

53

54

55

56

57

58

59

60

The reintroduction or relocation of wild-caught animals back into the wild can be an effective means for ecological restoration and population management (Van Wieren 2006; Teixeira et al. 2007). With climate change projections predicting alterations to current ecosystems and species assemblages, the translocation of taxa may become an increasingly important tool for preserving biodiversity and ecosystem functions in the future (Braidwood et al. 2018). However, many relocation programs are associated with unacceptably high rates of mortality among the released animals, and a leading cause of this problem is thought to be stress (Teixeira et al. 2007; Dickens et al. 2010). Animals collected for eventual release into the wild experience stress from multiple sources, including their capture, handling, transportation, housing, release, and possible acclimatization to a new environment (Teixeira et al. 2007; Parker et al. 2012). Despite the high priority placed on minimizing the stress associated with any one of these sources, the effects of multiple stressors can be additive and therefore still lead to increased mortality or decreased reproductive success after release (Moberg 2000).

Most organisms can tolerate acute but brief periods of stress, such as encounters with predators or exposure to short-term adverse environmental conditions (Brown et al. 2005; Teixeira et al. 2007). The behavioural and physiological changes observed during periods of acute stress are typically considered to be adaptive, as they tend to improve the odds of survival in response to immediate life-threatening situations (Romero and Wingfield 2015). However, capture and captivity can expose animals to acute and chronic stress (Morgan and Tromborg 2007) and can impose biological costs; to cope with a chronic stressor, individuals must redirect resources away from normal biological functions, which can influence somatic growth and maintenance (e.g., Lattin et al. 2012), reproduction (e.g., Lombardo and Thorpe 2009), and 
61 sometimes immune response (e.g., Buehler et al. 2008). Captive animals under stress may also

62 exhibit elevated heart rates and high levels of glucocorticoid hormones (e.g., Dickens and

63 Romero 2009; Fischer et al. 2018). Thus, any stress caused during the capture, handling, and

64 captive housing of wild animals can potentially have fitness consequences after their

65 reintroduction to the wild.

66 How long an animal can be held in captivity while minimizing stress and adverse effects

67 on survival and reproduction upon relocation back to the wild is a pertinent question in

68 conservation biology (Batson et al. 2017). Even short-term captivity, on the order of hours to

69 days, has been shown to cause a significant and detrimental stress response in some animals

70 (e.g., whistling frogs, Litoria ewingi, Coddington and Cree 1995; loggerhead sea turtles, Caretta

71 caretta, Gregory et al. 1996). To date, studies investigating the effects of stress on released

72 animals have largely focused on vertebrates - a pattern often seen in other branches of science

73 (Andrews 2011) and in conservation mandates - leaving a considerable gap in knowledge

74 pertaining to invertebrates.

75 Here, we examine whether time spent in captivity affects the behaviour of a wild-caught

76 invertebrate upon its release back into the wild. Using the red sea urchin Mesocentrotus

77 franciscanus as a model species, we investigated how short-term captivity of up to four days

78 affects three behaviours potentially related to fitness. Specifically, we examined their propensity

79 to aggregate and two anti-predation behaviours: self-righting and predator-escape responses. We

80 considered the propensity to aggregate as a potential index of feeding behaviour since several

81 species of sea urchins, including red sea urchins, aggregate in areas of patchy food sources such

82 as around drift algae (Lees 1970; Russo 1979; Vadas et al. 1986). Righting refers to the ability of

83 sea urchins to return to a normal 'oral surface down' position from an inverted position, which 
84 exposes the less-defended oral surface (Polls and Gonor 1975). Finally, a common escape

85

86

87 88

90

91

92

93

\section{Materials \& Methods}

95

96

97

\section{Ethics statement}

response of sea urchins in the presence of predatory sea stars is to rapidly move away (Vadas and Elner 2003; Urriago et al. 2011). We viewed any impairment of the righting or fleeing response as a potential increase in the vulnerability to predation of released sea urchins. We predicted that if captivity induces chronic stress, then the ability of sea urchins to perform these three key behaviours after release back into the wild should diminish as length of captivity (i.e., duration of stress) increases. Importantly, we also examined the individual effects of handling and tagging the animals, to distinguish them from the effects of captivity.

All procedures used in this study adhered to the ethical considerations and guidelines set by the Canadian Council on Animal Care (CCAC) and the animal ethics committee at the Bamfield Marine Sciences Centre (AUP UP16-SP-SCD-01 and UP16-SP-SCD-02).

\section{Urchin collection and captivity conditions}

A total of 198 red sea urchins were collected between 11 May and 17 May 2016 from Aguilar Point ( $48^{\circ} 50.381^{\prime} \mathrm{N}, 125^{\circ} 8.477^{\prime} \mathrm{S}$ ) near the Bamfield Marine Sciences Centre (BMSC) in British Columbia, Canada. Sea urchins were collected haphazardly by five pairs of scuba divers from depths ranging from $6-9 \mathrm{~m}$. We divided the collected sea urchins into five experimental groups, which were each held in captivity for differing lengths of time before release back into the wild: zero-day ( $n=38$, 'handling controls' described below), one-day $(n=40)$, two-day ( $n=$ $40)$, three-day $(n=40)$, and four-day $(n=40)$ captivity periods. Each group was collected on a 
109 different day to allow for a staggered release of the sea urchins back into the wild and to allow

110 time for follow-up behavioural testing post-release.

111 We transported all animals to be held in captivity (i.e., one- to four-day groups) in

112 seawater-filled coolers, and housed them at the BMSC in large, aerated water tables $(170 \times 70 \times$

$11320 \mathrm{~cm}$ ) fitted with a flow-through sea water system (water temperature: $11 \pm 0.5^{\circ} \mathrm{C}$ ). We placed

114 each experimental group in a separate water table. These groups were not fed for the duration of

115 their captivity, meaning that captivity co-occurred with food deprivation in our experiments.

116 While we did not parse out the specific consequences of starvation here, we did not expect that

117 such short-term food deprivations would dramatically impair urchin behaviour because sea

118 urchins are highly resilient to starvation. For example, both red sea urchins and purple sea

119 urchin, S. purpuratus have been shown to survive up to five months of starvation, although with

120 growth and reproductive consequences (Holland et al. 1967; Bureau 1996). On their day of

121 release, we measured the test diameter of each sea urchin to the nearest mm using calipers (mean

122 test diameter $\pm \mathrm{SD}=59.6 \pm 11.4 \mathrm{~mm}$, range $=23-95 \mathrm{~mm})$, and gave each sea urchin two

123 identically-coded silicon tags $(\sim 0.5 \times 0.5 \mathrm{~cm},<200 \mathrm{mg}$ in air, placed halfway down each of two

124 separate spines; Fig. 1), allowing us to identify individuals post-release in the wild. Sea urchins

125 in the 0-day 'handling control' group served as a procedural control, allowing us to separate the

126 effects of handling from those of captivity. These control animals were not held in captivity;

127 instead, they were held in water-filled coolers at the surface (for $\sim 1$ hour) while being tagged and

128 then immediately released.

129

130 Sea urchin release and behaviour assessment

131 Release of the experimental groups of tagged sea urchins occurred at the same site as they were

132 collected, at five anchored buoys placed $10 \mathrm{~m}$ apart at constant depth ( $\sim 6 \mathrm{~m}$ below chart datum). 
133 When the designated captivity period for an experimental group had elapsed, seven to eight sea

134 urchins were released using SCUBA at the base of each buoy (summing to $38-40$ sea urchins

135 per experimental group). Immediately following their release, we tested the ability of the sea

136 urchins to right themselves. To do this, we set each sea urchin with its aboral side down on a

137 relatively flat rock, and righting speed was measured as the time needed to return to their normal

138 position with their oral surface against the substrata. In a pilot study, we found that most sea

139 urchins could right themselves within $120 \mathrm{~s}$. We therefore set a 180-s limit for this assay and

140 recorded if any sea urchins were unable to right themselves in this time.

141 Twenty-four hours post-release, we relocated as many of the tagged sea urchins as

142 possible that we had released on the previous day by thoroughly searching the area within a 5-m

143 radius of each buoy, and more haphazardly searching the area beyond. Upon relocating a tagged

144 sea urchin, we assessed its propensity to aggregate with other sea urchins by counting the

145 number of other red sea urchins within a 1-m radius of the tagged animal. This method is a spot

146 estimate of density and we use it here as a proxy for local sea urchin aggregation (henceforth

147 called 'aggregation score'). Previous studies have similarly investigated sea urchin aggregation

148 at this spatial scale, i.e. by using $1 \mathrm{~m}^{2}$ quadrats (e.g., Russo 1979). Righting times were measured

149 again, as described above. Finally, we also measured each sea urchin's predator escape response

150 by placing the tagged sea urchin on a flat surface along a measuring tape and gently touching, for

151 approximately $1-2$ seconds, one side of the sea urchin with an arm of a predatory sunflower sea

152 star, Pycnopodia helianthoides (Mauzey et al. 1968). Such an action generates a chemosensory-

153 induced flight response in sea urchins that are preyed upon by $P$. helianthoides (Moitoza and

154 Phillips 1979). Predatory sea stars were collected earlier from the same location and were 50 - 
$15580 \mathrm{~mm}$ in diameter. The distance travelled by the sea urchin along the tape was measured for 30

$156 \mathrm{~s}$ after contact with the sea star.

157

158 Wild unhandled sea urchin controls

159 On each day that we tested the behaviour of our released (and relocated) treatment sea urchins

160 (i.e., the zero-day 'handling controls' as well as the one-day, two-day, three-day, and four-day

161 captives), we also conducted behavioural tests on wild, unhandled, and untagged sea urchins

162 found nearby. These sea urchins represented another control group, henceforth called 'wild

163 control', which allowed us to examine the effects of handling itself. Here, handling refers to the

164 actions of ascending with the animal to the surface for tagging and then descending again for

165 release. We selected every third untagged sea urchin (within the size range of the experimental

166 sea urchins) that we encountered while roving in the immediate vicinity of the anchored buoys.

167 The selected untagged sea urchins were also at least $1 \mathrm{~m}$ away from any other untagged sea

168 urchin that we had previously assessed. We measured the righting times, aggregation scores, and

169 predator escape responses for these wild control sea urchins (6-19 sea urchins tested per day for 170 a total of 64$)$.

171

172 Assessing the effects of tagging

173 To examine the effects of tagging, we collected an additional 20 red sea urchins from Aguilar

174 Point, which were kept for five days in individual tanks at BMSC fitted with flow-through sea

175 water and held at $11 \pm 0.5^{\circ} \mathrm{C}$. Ten of the sea urchins were tagged, as described above, and their

176 righting response was tested (as above, but with no time limit). The tags were then removed and

177 the righting time measured again. The order of testing was reversed for the other 10 individuals;

178 their righting times were measured without tags and then again after tagging. This series of 
179 behavioural tests was conducted on these individuals after one and five days of captivity, with 180 the sea urchins bearing tags for the duration in between their tests.

181

\section{Statistical analyses}

183 All analyses were performed in R version 3.4.4 (R Core Team 2018). Note that because of time 184 constraints while diving and the fact that not all tagged sea urchins could be relocated $24 \mathrm{~h}$ postrelease, sample sizes vary slightly across analyses.

We first tested whether the proportions of sea urchins that succeeded in righting

'handling control', one-day, two-day, three-day, and four-day captive) using chi-squared tests for equality of proportions (with Yate's continuity corrections). We then examined whether sea urchin righting times differed among experimental groups (for those sea urchins that righted themselves within 180 s). To do this, we fit two linear mixed-effects models (LMMs, 'nlme' R package, version 3.1-131.1, Pinheiro et al. 2018), one to the righting times measured immediately upon release and another to the righting times measured $24 \mathrm{~h}$ post-release. The responses were log-transformed to improve the normality and homoskedasticity of the model residuals based on Shapiro-Wilk tests and examination of standardized residuals versus fitted values plots. We included treatment group and test diameter as fixed effects and 'diver buddypair ID' as a random intercept to account for variation among divers in their handling of the animals and among sites where the data were collected. We then examined the following pairwise contrasts using Dunnett's comparisons: 1) wild controls versus each of the remaining experimental groups, and 2) handling controls versus each of the remaining experimental groups 201 (using 'glht' function in 'multcomp' R package, version 1.4-8, Hothorn et al. 2008). We then 202 tested whether urchin aggregation scores and predator escape responses differed among our 
203 experimental groups. To do this, we similarly fit LMMs to these data using the same fixed and

204 random effects structures as described previously and followed these up by examining pair-wise

205 Dunnett's contrasts.

206 Lastly, we tested whether the silicon tags used for individual identification in the wild

207 influenced sea urchin behaviour, in particular their righting times. We fit a LMM to the sea

208 urchin righting times measured in the lab (log-transformed). We included the day of behavioural

209 testing (i.e., day 1 vs. day 5), sea urchin test diameter, and tag status (i.e., tagged vs. untagged) as

210 fixed effects, as well as 'urchin ID' as a random intercept.

211

212

213

214

215

216

217

218

219

220

221

222

223

224

225

\section{Results}

\section{Effects of handling and captivity on sea urchin behaviour}

Overall, $12 \%$ of all sea urchins tested ( 31 out of 262 sea urchins) did not right themselves within $180 \mathrm{~s}$ on the first test (i.e., immediately upon release of captive sea urchins). There was initial variation in righting success among experimental group $\left(\chi^{2}=13.9, \mathrm{P}=0.016\right)$. This effect appeared to be largely driven by the high rate of righting failure of sea urchins in the handling control group ( $26 \%$, or 10 out of 38 sea urchins, vs $10 \%$ or 16 out of 160 sea urchins across other groups). When the handling control group was omitted, we no longer detected a difference between groups in righting success $\left(\chi^{2}=6.1, P=0.18\right)$. On the second test (24-hr post-release), only $8 \%$ of sea urchins did not right successfully (13 out of 163 sea urchins), and there was no difference among experimental groups in the proportions of sea urchins that successfully righted themselves $\left(\chi^{2}{ }_{5}=8.7, P=0.12\right)$. 

themselves than each group of handled and captive sea urchins tested immediately upon their release (LMM, all contrasts were at least: est. $\pm \mathrm{se}=0.19 \pm 0.04, z=4.4, P<0.001)$ (Fig. 2a).

229 230 231 232 233 234 235 236 237 238 239

240

241

242

Sea urchins that served as handling controls, i.e., tagged and released immediately, had similar righting times to all captive-held sea urchin groups upon release (all contrasts were at least: est. \pm se $=0.09 \pm 0.06, z=1.6, P=0.34)($ Fig. 2a). After $24 \mathrm{~h}$, wild controls were still significantly faster at righting themselves than the handling control group (est. $\pm \mathrm{se}=-0.44 \pm 0.14, z=-3.1, P$ $=0.01)$, the 1 -day (est. $\pm \mathrm{se}=0.48 \pm 0.13, z=3.7, P=0.001), 2$-day (est. $\pm \mathrm{se}=0.34 \pm 0.13, z=$ 2.6, $P=0.05$ ) and 4-day captive sea urchins (est. $\pm \mathrm{se}=0.36 \pm 0.13, z=2.8, P=0.03$ ), but not the 3 -day captive sea urchins (est. $\pm \mathrm{se}=0.23 \pm 0.13, z=1.8, P=0.26$ ) (Fig. 2b). The righting time of handling control sea urchins did not differ from those of any of the captive-held sea urchin groups after $24 \mathrm{~h}$ (all contrasts were at least: est. $\pm \mathrm{se}=-0.21 \pm 0.16, z=-1.3, P=0.52$ ) (Fig. 2b).

Mean aggregation scores for each sea urchin group varied from 13 to 17.4 individuals within a 1-m radius of a focal sea urchin. There were no detectable differences in sea urchin aggregation scores between any of the experimental groups and the wild controls (LMM: all contrasts were at least: est. $\pm \mathrm{se}=2.32 \pm 1.26, z=1.8, P=0.25$ ) or the handling controls (all contrasts were at least: est. \pm se $=3.38 \pm 1.41, z=2.4, P=0.06)$ (Fig. 3).

When induced to flee by contact from a predatory sea star, wild control sea urchins moved farther in $30 \mathrm{~s}$ than the 1-day (LMM: est. $\pm \mathrm{se}=5.39 \pm 1.98, z=2.7, P=0.03)$ and the 2day captive sea urchins (est. $\pm \mathrm{se}=5.53 \pm 2.00, z=2.8, P=0.03)$, but not the 3 -day (est. \pm se $=$ $4.10 \pm 1.96, z=2.1, P=0.15$ ) or 4 -day captive sea urchins (est. \pm se $=1.50 \pm 1.99, z=0.75, P=$ 0.93), or the handling control sea urchins (est. $\pm \mathrm{se}=5.20 \pm 2.14, z=2.4, P=0.07$ ) (Fig. 4). Sea 
249 urchins that served as handling controls had a similar predator escape response to the other

250 experimental groups (all contrasts were at least: est. \pm se $=3.70 \pm 2.22, z=1.7, P=0.30$ ).

251

252

253 Effect of tagging on sea urchin righting times

254 Red sea urchins in captivity took an average $( \pm \mathrm{SD})$ of $157 \mathrm{~s}( \pm 135 \mathrm{~s})$ to right themselves in the 255 laboratory. Tagging did not affect the sea urchins' ability to right themselves after one day or 256 five days of captivity (tagged vs untagged, LMM: est. $\pm \mathrm{se}=0.014 \pm 0.076, t_{58}=0.19, P=0.85$ ).

257 The length of captivity (1-day vs 5-days) also did not affect righting times (est. \pm se $=0.032 \pm$

$\left.2580.076, t_{58}=0.42, P=0.67\right)$. Larger sea urchins righted themselves faster than smaller sea urchins 259 (est. $\left.\pm \mathrm{se}=-0.009 \pm 0.003, t_{18}=-2.96, P=0.008\right)$.

260

261 Discussion

262 Using a series of behavioural tests conducted in the field and in the laboratory, we examined the 263 effects of handling, tagging, and captivity on the behaviour of wild-caught and released red sea 264 urchins. We show that handling the animals impaired, at least in the short term, two of the three 265 behaviours examined: self-righting and predator escape speed. Tagging had no effect on the 266 righting behaviour of captive sea urchins, and the length of captivity (i.e., the length of the 267 putative stress period) did not have a detectable effect on sea urchin behaviour post-release, for 268 periods of up to four days of captivity. The detectable effect of handling in combination with a 269 lack of effect of duration of captivity suggests that starvation - a potentially confounding factor 270 in our experiments - played little or no role in altering sea urchin behaviour. Longer-term 271 monitoring of survival and reproduction of released animals is needed to establish whether the 272 short-term behavioural impairments observed have fitness consequences. 
274 predatory sea star stimulus (i.e., they exhibited a flight response). This suggests that the primary

275 anti-predator behaviour among our sampled population of sea urchins was to flee as opposed to

276 stay and combat the sea star with their spines (an alternative anti-predator defence behaviour of

277 M. franciscanus suggested by Moitoza and Phillips 1979). We show that wild, unhandled red sea

278 urchins were faster at moving away from the predator stimulus than sea urchins that were first

279 handled, including those that were handled and held in captivity. Handled and captive-held sea

280 urchins were also slower at righting themselves, and these effects persisted for at least one day

281 after release. Thus, sea urchins that experienced capture and handling might be more susceptible

282 to predation than their unhandled counterparts after release. Impaired anti-predator behaviour has

283 been noted in captured animals that are subsequently released (e.g., Raby et al. 2014). For

284 example, wild reef fish that were caught and taken out of water took longer to reach the reef and

285 to seek shelter after being released than wild fish exposed to less stressful conditions (Raby et al.

286 2018). Caribbean spiny lobster Panulirus argus captured and released by divers abandoned

287 previously occupied shelters, which might have contributed to their decreased survival when

288 predators were present (Parsons and Eggleston 2006). Similarly, translocated cane toads Rhinella

289 marina selected shallower shelters and spent more time visible by day than resident toads, which

290 might have made the former easier for predators to locate (Pettitt et al. 2017). At least in

291 vertebrates, post-release behavioural deficiencies are usually ascribed to physiological,

292 locomotory and/or cognitive impairments associated with the stress of capture (Cooke et al.

293 2013; Raby et al. 2014).

294 Animals that are captured to be released at a later date are sometimes tagged to allow

295 subsequent recognition and monitoring. Tagging can cause a number of behavioural alterations, 
296 ranging from changes in foraging, parental care, movement and habitat choice (Walker et al.

297 2011; Jepsen et al. 2015), but disentangling the effects of tagging from those of capture and

298 captivity can be challenging and is seldom done (Jepsen et al. 2015). We were able to show that 299 tagging sea urchins had a non-detectable effect on their righting times in the laboratory. This 300 result lends confidence that the slower righting times of captured and released sea urchins were 301 not due to tagging but to handling, which in our case meant bringing the animals to the surface 302 from depths of $6-9 \mathrm{~m}$ for $\sim 1 \mathrm{~h}$ and releasing them back to the capture point. The tags we used 303 likely did not have a behavioural effect on red sea urchins because they were non-invasive (see 304 also Dumont et al. 2006, who used beaded monofilament on the sea urchin Strongylocentrotus 305 droebachiensis). In contrast, more invasive tags, such as internal tags or branding, can have marked effects on the behaviour, growth and survival of sea urchins (Lauzon-Guay and Scheibling 2008) and other aquatic invertebrates (e.g., Wilson et al. 2011; Martinez et al. 2013). might increase as the length of captivity, or stress period, increased. This was not the case. The duration of captivity had no detectable effect on sea urchin righting time, either upon release or $24 \mathrm{~h}$ later. In contrast, the predator escape response of released sea urchins appeared to improve

312 after two days in captivity, such that sea urchins that had been in captivity for three or four days 313 moved away from the predator stimulus at similar speeds to unhandled wild sea urchins. Our 314 behavioural results therefore suggest a possible reversal of the stress state of sea urchins held in 315 captivity for more than $48 \mathrm{~h}$. In many vertebrates, the initial hours or days of captivity can result 316 in weight loss, increases in stress hormone (i.e., cortisol, corticosterone) concentrations, and 317 disruption of the negative feedbacks controlling stress hormone production (e.g., Davidson 1984; 318 Coddington and Cree 1995; Davidson et al. 1997; Dickens et al. 2009; Adams et al. 2010). 
319 However, these changes can reverse after a few days of captivity as seen in some species of

320 birds, for example after three days in North Island saddlebacks, Philesturnus rufusater (Adams et

321 al. 2010) and nine days in chukar, Alectoris chukar (Dickens et al. 2009), indicating acclimation

322 to captive conditions. To our knowledge, a similar pattern has not been previously noted in

323 invertebrates. Future studies should investigate the effects of longer periods of captivity, and

324 assay a suite of stress responses and behaviours involved in foraging, reproduction, and defense

325 against multiple predator types, to determine the generality and trend shape (i.e., stepwise or

326 gradual) of potential acclimation to captivity in invertebrates.

$327 \quad$ While handling affected the self-righting and predator escape responses of red sea

328 urchins, neither handling nor captivity altered their propensity to aggregate with conspecifics.

329 Aggregation in this species and in other sea urchins has been shown to be closely associated with 330 food abundance (Russo 1979; Vadas et al. 1986). We had therefore hypothesised that stress from

331 handling and captivity might diminish foraging behaviour, as it sometimes does in vertebrates

332 (Morgan and Tromborg 2007), leading to reduced aggregation. It is possible that no effect was

333 observed because the link between sea urchin foraging and aggregation is geographically or

334 seasonally variable (e.g., Lauzon-Guay and Scheibling 2007) or strongly modified by biotic

335 factors, such as the presence of predators or the dispersion of food sources (e.g., Bernstein et al.

336 1983). The high density of red sea urchins and the dispersed distribution of kelp (personal

337 observations) at our study site might have reduced the incentive for sea urchins to aggregate.

338 Overall, our results indicate that the duration of (short-term) captivity does not cause

339 detrimental effects on the post-release behaviour of wild-caught red sea urchins, at least for those

340 behaviours we tested. However, handling alters behaviours, at least in the short term, that could

341 have fitness consequences, although longer-term studies on behaviour, reproduction and survival 
342 will be needed to verify this. Two of the three behaviours examined were affected, highlighting

343 the usefulness of considering a suite of responses. While there might be limited interest, other

344 than for scientific study, in the capture and release of a species as abundant as M. franciscanus,

345 our findings could inform conservation efforts aimed at ecologically similar but depleted species.

346 Examples include the Caribbean long-spined sea urchin, Diadema antillarum, decimated by

347 disease in the 1980s (Lessios 1988), and the European purple sea urchin, Paracentrotus lividus,

348 which has collapsed in parts of the Mediterranean Sea due to disease linked to warming

349 temperatures (Girard et al. 2012; Yeruham et al. 2015). Translocation of individuals of such

350 species could bolster local populations or concentrate remaining individuals in more favourable

351 habitats, restoring the ecosystem functions (e.g., herbivory) provided by these ecologically

352 important species.

353

354 Acknowledgements

355 We thank the Huu-ay-aht First Nations for their permission to sample sea urchins from their 356 territory, and the Bamfield Marine Sciences Centre (BMSC) and its staff for their time,

357 resources, use of animal-holding facilities, and hospitality. Thank you to Steve Johnson and

358 Janice Pierce for providing boat tending and surface safety support during diving sessions.

359

360

361

362

\section{References}

363 Adams NJ, Parker KA, Cockrem JF, Brunton DH, Candy EJ (2010) Corticosterone responses and post-release survival in translocated North Island Saddlebacks (Philesturnus rufusater) in New Zealand. Emu 110:296-301. doi: 10.1071/MU09084 
366 Andrews PL (2011) Laboratory invertebrates: Only spineless, or spineless and painless. ILAR J

367

368

369

370

371

372

373

374

375

376

377

378

379

380

381

382

383

384

385

386

387

388 52:121-125

Batson WG, Gordon IJ, Fletcher DB, Portas TJ, Manning AD (2017) The effect of pre-release captivity on the stress physiology of a reintroduced population of wild eastern bettongs. $\mathrm{J}$ Zool 303:311-319. doi: 10.1111/jzo.12494

Bernstein BB, Schroeter SC, Mann KH (1983) Sea urchin (Strongylocentrotus droebachiensis) aggregating behavior investigated by a subtidal multifactorial experiment. Can J Fish Aquat Sci 40:1975-1986. doi: 10.1139/f83-227

Braidwood DW, Taggart MA, Smith M, Andersen R (2018) Translocations, conservation, and climate change: use of restoration sites as protorefuges and protorefugia. Restor Ecol 26:208. doi: doi:10.1111/rec.12642.

Brown C, Gardner C, Braithwaite VA (2005) Differential stress responses in fish from areas of high-and low-predation pressure. J Comp Physiol B 175:305-312. doi: 10.1007/s00360-0050486-0

Buehler DM, Bhola N, Barjaktarov D, Goymann W, Schwabl I, Tieleman B I, Piersma T (2008) Constitutive immune function responds more slowly to handling stress than corticosterone in a shorebird. Physiol Biochem Zool 81:673-681. doi: 10.1086/588591

Bureau, D. 1996. Relationship between feeding, reproductive condition, jaw size and density in the red sea urchin, Strongylocentrotus franciscanus. M.Sc. thesis, Simon Fraser University, $102 \mathrm{pp}$.

Coddington EJ, Cree A (1995) Effect of acute captivity stress on plasma concentrations of corticosterone and sex steroids in female whistling frogs, Litoria ewingi. Gen Comp Endocrinol 100:33-38. doi: 10.1006/gcen.1995.1129 
389 Cooke SJ, Messmer V, Tobin AJ, Pratchett MS, Clark TD (2013) Refuge-seeking impairments 390 mirror metabolic recovery following fisheries-related stressors in the Spanish flag snapper 391 (Lutjanus carponotatus) on the Great Barrier Reef. Physiol Biochem Zool 87:136-147. doi: $392 \quad 10.1086 / 671166$

393 Davidson NC (1984) Changes in the condition of dunlins and knots during short-term captivity. 394 Can J Zool 62:1724-1731. doi: 10.1139/z84-253

395 Davidson GW, Thorarensen HT, Lokman M, Davie PS (1997) Stress of capture and captivity in 396 kahawai Arripis trutta (Bloch and Schneider)(Perciformes: Arripidae). Comp Biochem 397 Physiol A: Physiol 118:1405-1410. doi: 10.1016/S0300-9629(97)86806-5

398 Dickens MJ, Romero LM (2009) Wild European starlings (Sturnus vulgaris) adjust to captivity 399 with sustained sympathetic nervous system drive and a reduced fight-or-flight response. $400 \quad$ Physiol Biochem Zool 82:603-610. doi: 10.1086/603633

401 Dickens MJ, Earle KA, Romero LM (2009) Initial transference of wild birds to captivity alters 402 stress physiology. Gen Comp Endocrinol 160:76-83. doi: 10.1016/j.ygcen.2008.10.023

403 Dickens MJ, Delehanty DJ, Romero LM (2010) Stress: an inevitable component of animal 404 translocation. Biol Conserv 143:1329-1341. doi: 10.1016/j.biocon.2010.02.032

405 Dumont CP, Himmelman JH, Russell MP (2006) Daily movement of the sea urchin 406 Strongylocentrotus droebachiensis in different subtidal habitats in eastern Canada. Mar Ecol 407 Progr Ser 317:87-99. doi: 10.3354/meps317087

408 Fischer CP, Wright-Lichter J, Romero LM (2018) Chronic stress and the introduction to 409 captivity: how wild house sparrows (Passer domesticus) adjust to laboratory conditions. $410 \quad$ Gen Comp Endocrinol 259:85-92. doi: 10.1016/j.ygcen.2017.11.007 
411 Girard D, Clemente S, Toledo-Guedes K, Brito A, Hernández JC (2012) A mass mortality of

412 subtropical intertidal populations of the sea urchin Paracentrotus lividus: analysis of

413 potential links with environmental conditions. Mar Ecol 33:377-385. doi: 10.1111/j.1439-

$414 \quad$ 0485.2011.00491.x

415 Gregory LF, Gross TS, Bolten AB, Bjorndal KA, Guillette Jr LJ (1996) Plasma corticosterone

416 concentrations associated with acute captivity stress in wild loggerhead sea turtles (Caretta

417 caretta). Gen Comp Endocrinol 104:312-320. doi: 10.1006/gcen.1996.0176

418 Holland LZ, Giese AC, Phillips JH (1967) Studies on the perivisceral coelomic fluid protein

419 concentration during seasonal and nutritional changes in the purple sea urchin. Comp

420 Biochem Physiol 21: 361-371. doi: 10.1016/0010-406X(67)90798-0

421 Hothorn T, Bretz F, Westfall P (2008) Simultaneous inference in general parametric models.

422 Biometric J 50:346-363. doi: 10.1002/bimj.200810425

423 Jepsen N, Thorstad EB, Havn T, Lucas MC (2015) The use of external electronic tags on fish: an

424 evaluation of tag retention and tagging effects. Anim Biotelem 3:49. doi: 10.1186/s40317-

$425 \quad 015-0086-z$

426 Lattin CR, Bauer CM, de Bruijn R, Romero LM (2012) Hypothalamus-pituitary-adrenal axis

427 activity and the subsequent response to chronic stress differ depending upon life history

428 stage. Gen Comp Endocrinol 178:494-501. doi: 10.1016/j.ygcen.2012.07.013

429 Lauzon-Guay JS, Scheibling RE (2007) Seasonal variation in movement, aggregation and

430 destructive grazing of the green sea urchin (Strongylocentrotus droebachiensis) in relation

431 to wave action and sea temperature. Mar Biol 151:2109. doi: 10.1007/s00227-007-0668-2

432 Lauzon-Guay JS, Scheibling RE (2008) Evaluation of passive integrated transponder (PIT) tags

433 in studies of sea urchins: caution advised. Aquat Biol 2:105-112. doi: 10.3354/ab00040 
434 Lees DC (1970) The relationship between movement and available food in the sea urchins 435 Strongylocentrotus franciscanus and Strongylocentrotus purpuratus. MSc. Thesis, San 436 Diego State College, San Diego, pp. 1-119.

437 Lessios HA (1988) Mass mortality of Diadema antillarum in the Caribbean: what have we 438 learned? Ann Rev Ecol Syst 19:371-393. doi: 10.1146/annurev.es. 19.110188.002103 439 Lombardo MP, Thorpe PA (2009) Captivity affects sperm production, testes size and beak color 440 in house sparrows (Passer domesticus). Intl Stud Sparrows 33:5-16.

441 Martinez AS, Byrne M, Coleman RA (2013) Unique tagging of small echinoderms: a case study 442 using the cushion star Parvulastra exigua. Methods Ecol Evol 4:993-1000. doi: 10.1111/2041-210X.12099

444 445

446

447

448

449

450

451

452

453

454

455

Mauzey KP, Birkeland C, Dayton PK (1968) Feeding behavior of asteroids and escape responses of their prey in the Puget Sound region. Ecology 49:603-619. doi: 10.2307/1935526

Moitoza DJ, Phillips DW (1979) Prey defense, predator preference, and nonrandom diet: the interactions between Pycnopodia helianthoides and two species of sea urchins. Mar Biol 53:299-304. doi: 10.1007/BF00391611

Moberg GP (2000) Biological response to stress: implications for animal welfare. In: Moberg GP, Mench JA (eds) The biology of animal stress: basic principles and implications for animal welfare. CABI, New York, pp 1-21

Morgan KN, Tromborg CT (2007) Sources of stress in captivity. Appl Anim Behav Sci 102:262302. doi: 10.1016/j.applanim.2006.05.032

Parker KA, Dickens MJ, Clarke RH, Lovegrove TG, Ewen JG, Armstrong DP (2012) The theory and practice of catching, holding, moving and releasing animals. In: Ewen JG, Armstrong 
456

457

458

459

460

461

462

463

464

465

466

467

DP, Parker KA, Seddon PJ (eds) Reintroduction biology: integrating science and management. Wiley, West Sussex, pp 105-136

Parsons DM, Eggleston DB (2006) Human and natural predators combine to alter behavior and reduce survival of Caribbean spiny lobster. J Exp Mar Biol Ecol 334:196-205. doi: 10.1016/j.jembe.2006.01.020

Pettit LJ, Greenlees MJ, Shine R (2017) The behavioural consequences of translocation: how do invasive cane toads (Rhinella marina) respond to transport and release to novel environments? Behav Ecol Sociobiol 71:15. doi: 10.1007/s00265-016-2245-5

Pinheiro J, Bates D, DebRoy S, Sarkar D, R Core Team (2018) nlme: linear and nonlinear mixed effects models. R package version 3.1-131.1, URL: https://CRAN.Rproject.org/package $=$ nlme.

Polls I, Gonor J (1975) Behavioral aspects of righting in two asteroids from the Pacific coast of North America. Biol Bull 148:68-84. doi: 10.2307/1540651

R Core Team (2018) R: A language and environment for statistical computing. R Foundation for Statistical Computing, Vienna, Austria. URL: http://www.R-project.org/

Raby GD, Packer JR, Danylchuk AJ, Cooke SJ (2014) The understudied and underappreciated role of predation in the mortality of fish released from fishing gears. Fish Fish 15:489-505. doi: $10.1111 /$ faf. 12033

Raby GD, Messmer V, Tobin AJ, Hoey AS, Jutfelt F, Sundin J, Cooke SJ, Clark TD (2018) Swim for it: effects of simulated fisheries capture on the post-release behaviour of four Great Barrier Reef fishes. Fish Res 206:129-137. doi: 10.1016/j.fishres.2018.05.012

Romero LM, Wingfield JC (2015) Tempests, poxes, predators, and people: stress in wild animals and how they cope. Oxford University Press, Oxford 
479 Russo AR (1979) Dispersion and food differences between two populations of the sea urchin 480 Strongylocentrotus franciscanus. J Biogeogr 6:407-414. doi: 10.2307/3038092

481 Teixeira CP, De Azevedo CS, Mendl M, Cipreste CF, Young RJ (2007) Revisiting translocation 482 and reintroduction programmes: the importance of considering stress. Anim Behav 73:1-13. 483 doi: 10.1016/j.anbehav.2006.06.002

484 Urriago JD, Himmelman JH, Gaymer CF (2011) Responses of the black sea urchin Tetrapygus 485 niger to its sea-star predators Heliaster helianthus and Meyenaster gelatinosus under field 486 conditions. J Exp Mar Biol Ecol 399:17-24. doi: 10.1016/j.jembe.2011.01.004

487 Vadas Sr RL, Elner RW (2003) Responses to predation cues and food in two species of 488 sympatric, tropical sea urchins. Mar Ecol 24:101-121. doi: 10.1046/j.1439$489 \quad 0485.2003 .03817 . x$

490 Vadas RL, Elner RW, Garwood PE, Babb IG (1986) Experimental evaluation of aggregation 491 behavior in the sea urchin Strongylocentrotus droebachiensis. Mar Biol 90:433-448. doi: 492 10.1007/BF00428567

Van Wieren SE (2006) Populations: re-introductions. In: Van Andel J, Aronson J (eds), Restoration ecology: the new frontier. Blackwell, Australia, pp. 82-92

Walker KA, Trites AW, Haulena M, Weary DM (2012) A review of the effects of different marking and tagging techniques on marine mammals. Wildl Res 39:15-30. doi: 10.1071/WR10177 bivalves for translocation induces short-term behavioural costs. Anim Behav 81:341-346.

$500 \quad$ doi: $10.1016 /$ j.anbehav.2010.10.003 
501 Yeruham E, Rilov G, Shpigel M, Abelson A (2015) Collapse of the echinoid Paracentrotus

502 lividus populations in the Eastern Mediterranean-result of climate change? Sci Re

$503 \quad 5: 13479$. doi: $10.1038 /$ srep 13479

504 


\section{Figure captions}

506

507 Figure 1 Tagged red sea urchin released in the wild. Every urchin was marked with

508 individually numbered silicon tags. Photo credit: I.M. Côté

509

510 Figure 2 Sea urchin righting times measured (a) immediately after release into the wild and

511 (b) 24 h post-release. Capital letters denote the results of comparisons between 'wild' controls

512 as the reference group and all other experimental groups; lowercase letters denote the results of

513 comparisons between 'handling' controls as the reference group and all captive experimental

514 groups. Within a comparison set, means with similar letters are not significantly different from

515 the reference group. Bars represent means \pm standard error (in s). Sample sizes per group are 516 given above each bar in parentheses.

517

518 Figure 3 Sea urchin aggregation scores. Capital letters denote the results of comparisons

519 between 'wild' controls as the reference group and all other experimental groups; lowercase

520 letters denote the results of comparisons between 'handling' controls as the reference group and

521 all captive experimental groups. Within a comparison set, means with similar letters are not

522 significantly different from the reference group. Bars represent means \pm standard error. Sample

523 sizes per group are given above each bar in parentheses. Aggregation scores were obtained by

524 counting the number of sea urchins within a one-meter radius of focal urchins on each sampling 525 day.

526 
527 Figure 4 Distance travelled by sea urchins in $30 \mathrm{~s}$ after being induced to flee by contact

528 with a predatory sea star. Capital letters denote the results of comparisons between 'wild'

529 controls as the reference group and all other experimental groups; lowercase letters denote the

530 results of comparisons between 'handling' controls as the reference group and all captive

531 experimental groups. Within a comparison set, means with similar letters are not significantly

532 different from the reference group. Bars represent means \pm standard error (in $\mathrm{cm}$ ). Sample sizes

533 per group are given above each bar in parentheses. 


\section{Figure 1}

Tagged red sea urchin released in the wild

Every urchin was marked with individually numbered silicon tags. Photo credit: I.M. Côté 


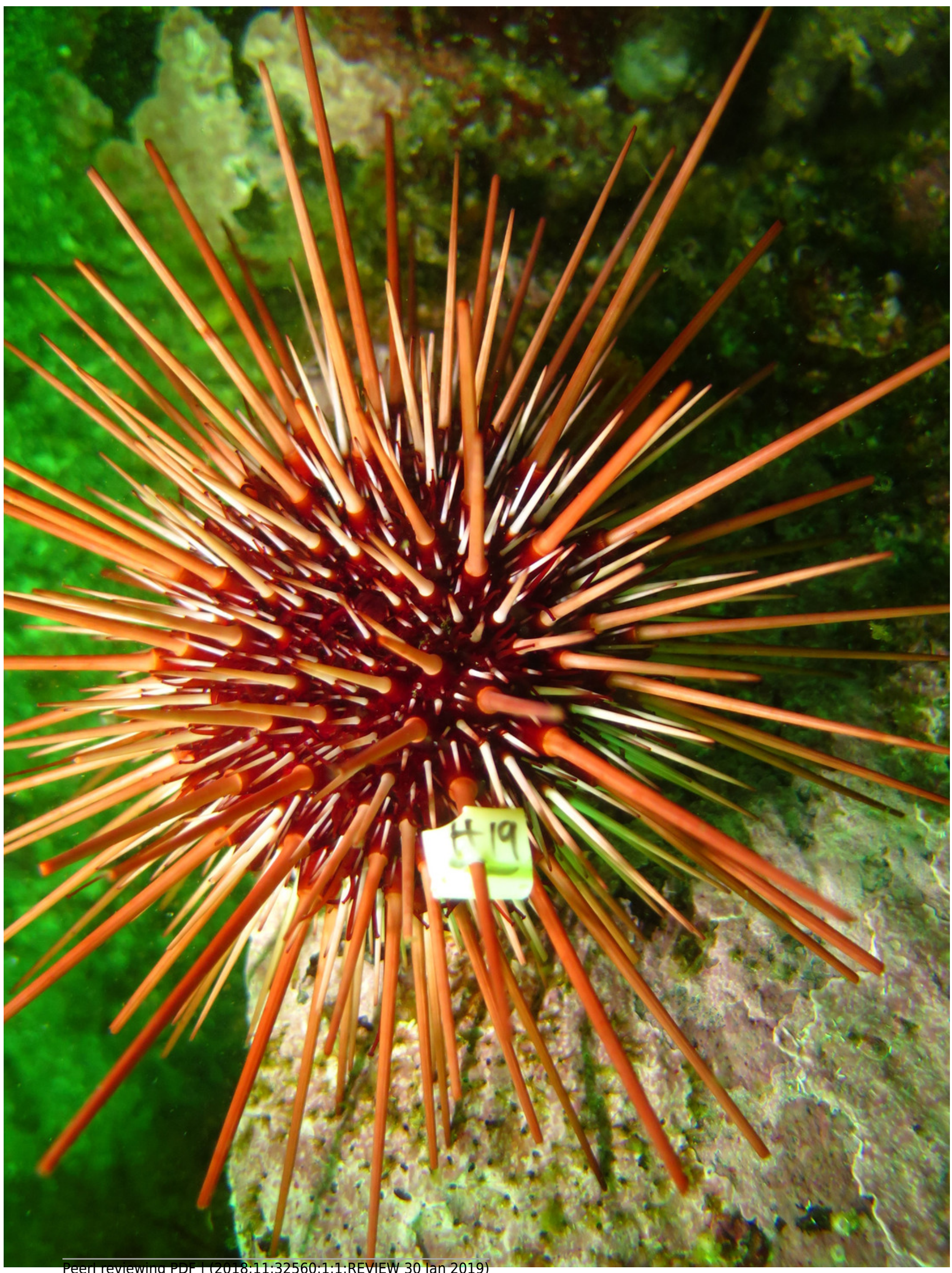


Figure 2 (on next page)

Sea urchin righting times measured (a) immediately after release into the wild and (b) $24 \mathrm{~h}$ post-release.

Capital letters denote the results of comparisons between 'wild' controls as the reference group and all other experimental groups; lowercase letters denote the results of comparisons between 'handling' controls as the reference group and all captive experimental groups. Within a comparison set, means with similar letters are not significantly different from the reference group. Bars represent means \pm standard error (in s). Sample sizes per group are given above each bar in parentheses. 


\section{Figure 3 (on next page)}

Sea urchin aggregation scores.

Capital letters denote the results of comparisons between 'wild' controls as the reference group and all other experimental groups; lowercase letters denote the results of comparisons between 'handling' controls as the reference group and all captive experimental groups. Within a comparison set, means with similar letters are not significantly different from the reference group. Bars represent means \pm standard error. Sample sizes per group are given above each bar in parentheses. Aggregation scores were obtained by counting the number of sea urchins within a one-meter radius of focal urchins on each sampling day. 
Figure 4 (on next page)

Distance travelled by sea urchins in $30 \mathrm{~s}$ after being induced to flee by contact with a predatory sea star.

Capital letters denote the results of comparisons between 'wild' controls as the reference group and all other experimental groups; lowercase letters denote the results of comparisons between 'handling' controls as the reference group and all captive experimental groups. Within a comparison set, means with similar letters are not significantly different from the reference group. Bars represent means \pm standard error (in $\mathrm{cm}$ ). Sample sizes per group are given above each bar in parentheses 


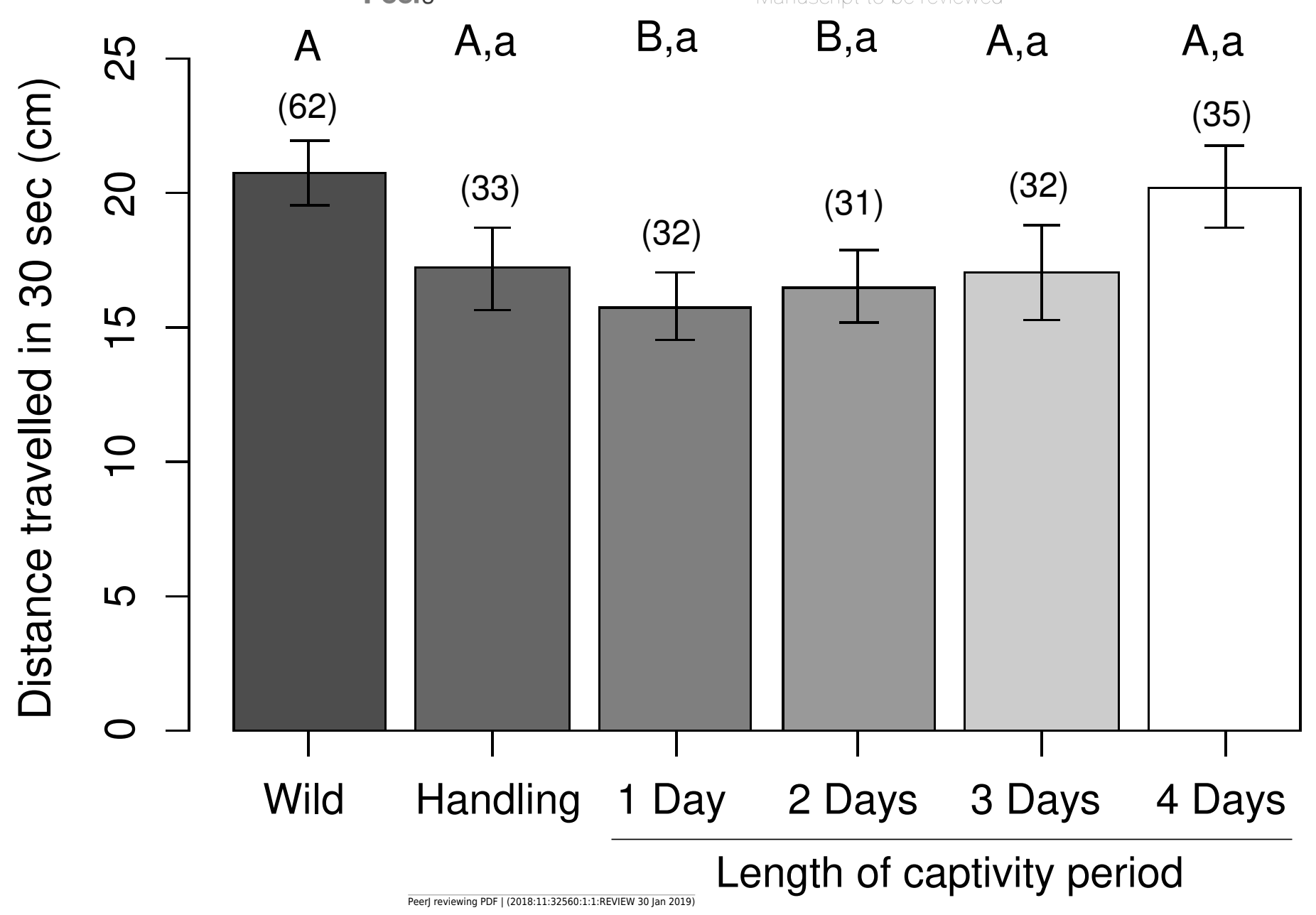

